\title{
Gingival Leiomyosarcoma in a Young Woman Case report and literature review
}

Massimo Viviano, ${ }^{1}$ Clelia Miracco, ${ }^{2}$ Guido Lorenzini, ${ }^{3}$ Gennaro Baldino, ${ }^{2}$ Serena Cocca $^{4}$

$$
\text { ساركوما عضلية ملساء عند شابة }
$$

ماسيمو فيفانيو، سليليا ميراكو، جودو لوريزيني، جينارو بالدينو، سيرينا كوكا

ABSTRACT: Leiomyosarcoma (LMS) is a rare mesenchymal malignancy, of which $3-10 \%$ of cases occur in the head and neck region. We report a 22-year-old woman who was referred to the University Hospital of Siena, Italy, in 2016 with an ostensibly benign asymptomatic lump on the mandibular gingiva. The lesion grew rapidly, causing otalgia in the right ear. An excisional biopsy was performed and primary LMS was diagnosed histologically. Subsequently, the patient underwent radical re-excision of the perilesional mucosa, a partial bone resection and the extraction of four teeth. No recurrences or metastases were detectable at a 20-month follow-up. This report discusses the differential diagnosis of LMS with regards to other benign and malignant lesions and reviews the recent literature on primary and secondary oral LMS. Due to its innocuous clinical features-including its asymptomatic nature and presentation at a young age-this aggressive malignancy can go undetected; therefore, an early histopathological diagnosis is crucial.

Keywords: Leiomyosarcoma; Soft Tissue Neoplasms; Gingival Neoplasms; Smooth Muscle Tumors; Otalgia; Immunohistochemistry; Case Report; Italy.

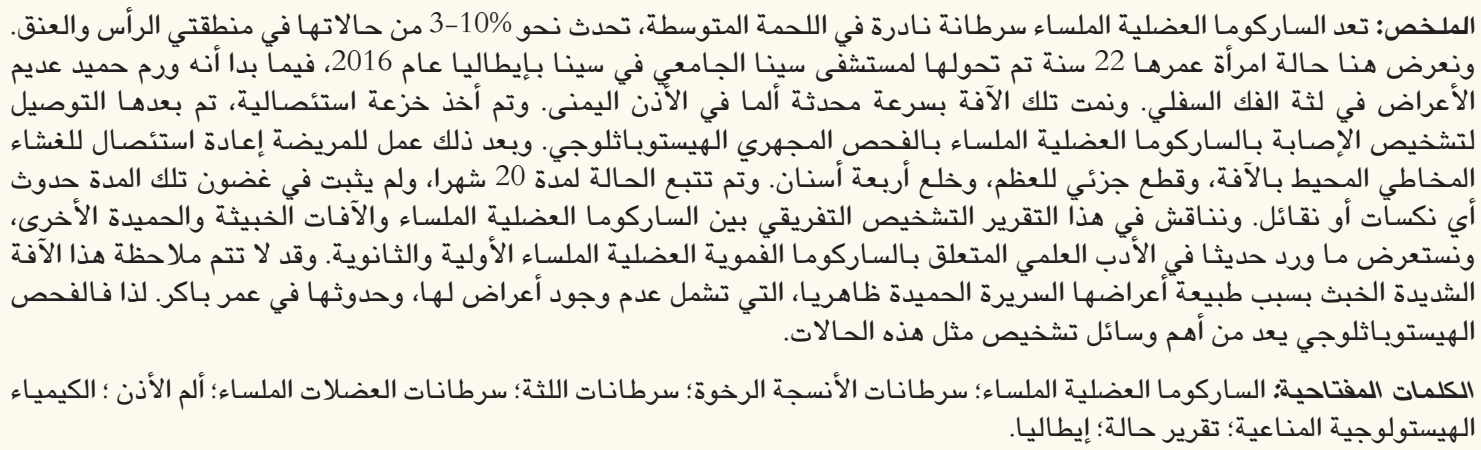

C

ONSTituting 6-7\% OF ALL SOFT Tissue sarcomas, leiomyosarcoma (LMS) is a malignant tumour of mesenchymal origin which occurs very rarely in the oral cavity, with only $3-10 \%$ of cases arising in the head and neck region. ${ }^{1,2}$ Oral LMS arises primarily in the bones and soft tissue and is reported predominantly among adult patients, without any significant gender predominance. ${ }^{3}$ The aetiology of this entity remains uncertain, with suggested causes including trauma, oestrogen stimulation, ionising radiation and Epstein-Barr virus infections. ${ }^{3-5}$ The sarcoma has an aggressive growth pattern and a high rate of recurrence due to its dissemination in the bloodstream. ${ }^{5}$ The presenting signs of oral LMS are generally nonspecific and the similarity of this entity to certain benign lesions typically delays its diagnosis.
This report presents a case of oral LMS in a young patient which was rapidly diagnosed and resulted in a positive outcome. As the patient was disease-free following radical surgical excision, further surgery, chemotherapy or radiation therapy was avoided.

\section{Case Report}

A 22-year-old Caucasian woman was referred to the Department of Dentistry at the University Hospital of Siena, Italy, in 2016 with otalgia in the right ear and an asymptomatic swelling on the lower right lingual gingiva, which she had initially noticed approximately one month beforehand. The patient's medical history indicated that she was in good health and was not currently taking any medication. An examination of the 


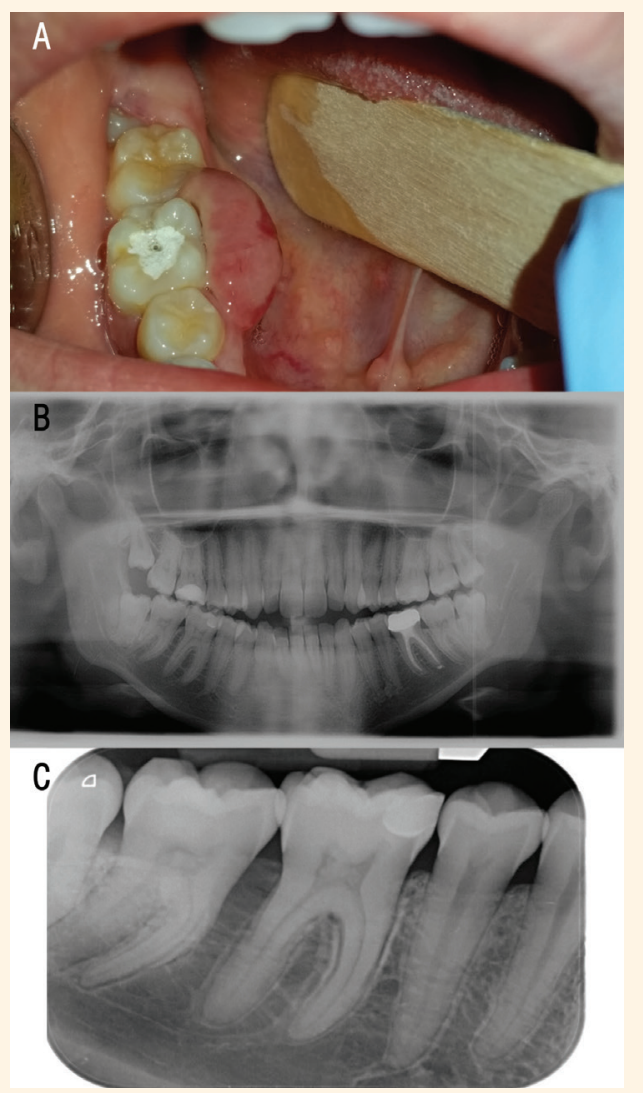

Figure 1: A: Intraoral photograph of a 22-year-old woman with an asymptomatic gingival lesion. B: Preoperative orthopantomogram of the lesion showing no abnormalities. C: Preoperative periapical X-ray of the mandibular right molar which also appears normal.

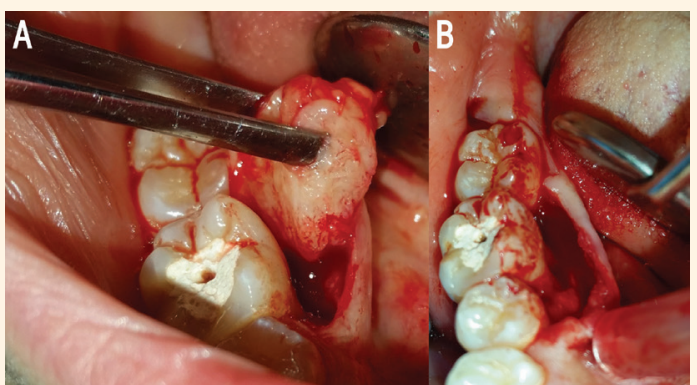

Figure 2: Intraoral photographs of a 22-year-old woman undergoing an excisional biopsy of an asymptomatic gingival lesion in which (A) the lesion was radically resected under local anaesthesia, leaving (B) the apparently healthy teeth, gingiva and alveolar bone intact.

oral cavity revealed a hard, non-painful, reddish-pink, non-haemorrhagic gingival swelling around the first lower right molar (i.e. tooth number 46) [Figure 1A]. The rest of the ear, nose and throat examination was normal. An orthopantomogram and periapical X-ray of tooth number 46 appeared normal [Figures $1 \mathrm{~B}$ and C]. An excisional biopsy was subsequently performed under local anaesthesia, with the excised lesion measuring $1.5 \times 1.2 \mathrm{~cm}$ [Figure 2]. Following the surgery, the patient was prescribed a six-day course of
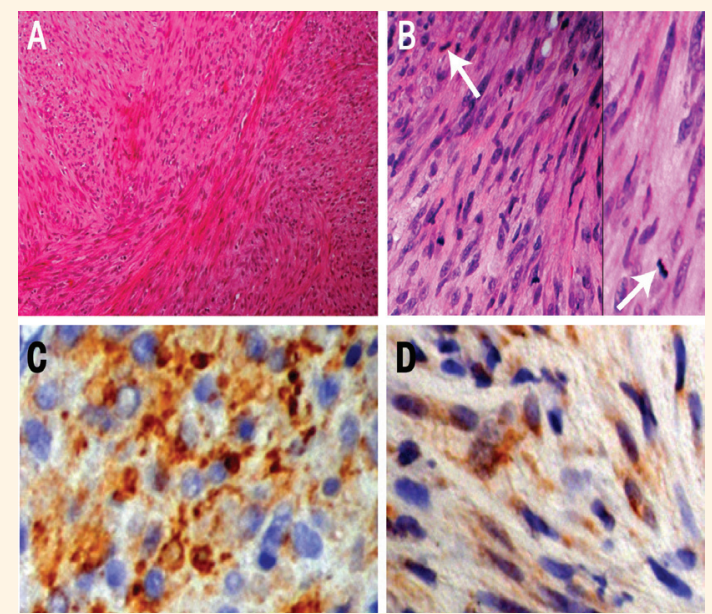

Figure 3: A: Haematoxylin and eosin stain (H\&E) at x100 magnification showing a leiomyosarcoma composed of perpendicularly oriented fascicles of spindle cells. B: H\&E stain at x200 magnification showing deep eosinophilic cytoplasm and elongated blunt-ended nuclei with mitoses (arrows). C and D: Immunohistochemistry chromogen diaminobenzidine stains at x200 magnification showing diffuse cytoplasmic positivity for smooth muscle actin antibodies and h-caldesmon, respectively.

antibiotics consisting of $1 \mathrm{~g}$ of amoxicillin and clavulanic acid twice daily.

The excised mass was fixed in buffered formalin. A histopathological examination showed an unencapsulated tumour with pushing margins and an absence of infiltrative growth patterns. The lesion consisted of bundles of spindle cells intersecting at right angles, with well-defined brightly eosinophilic cytoplasm, cigar-shaped pleomorphic nuclei and occasional paranuclear vacuoles [Figure 3A]. There were a few microfoci of coagulative necrosis and $13-15^{10}$ mitoses in a high-power field at $\times 400$ magnification (corresponding to about $1 \mathrm{~mm}^{2}$ ) [Figure 3B]. Immunohistochemistry was performed on 3- $\mu$ m-thick sections using the BenchMark ULTRA ${ }^{\circledR}$ automated staining system (Ventana Medical Systems Inc., Roche Diagnostics, Monza, Italy). The ultraView Universal DAB Detection $\mathrm{Kit}^{\circledR}$ (Ventana Medical Systems Inc.) was used with horseradish peroxidase multimer chromogen diaminobenzidine in order to stain positive structures brown. The neoplastic cells were positive for smooth muscle markers, including h-caldesmon (clone e89), HHF35, myosin, smooth muscle actin (clone 1A4) and smooth muscle myosin monoclonal antibody-1 [Figures 3C and D]. The Ki-67 labelling index (clone MIB-1) was approximately 30-40\%. All other tested antibodies were negative, including activin receptorlike kinase, cluster of differentiation (CD)34, c-Kit, desmin, DOG1, oestrogen receptors, pankeratin, progesterone receptors, skeletal muscle actin and S100 


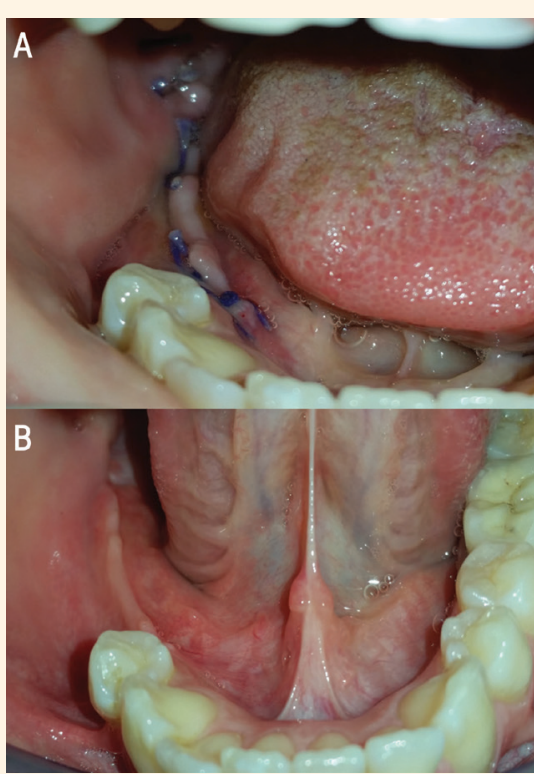

Figure 4: Intraoral photographs of a 22-year-old woman (A) immediately after radical surgical bone resection and the extraction of teeth number 45-48 and (B) 20 months later with no evidence of recurrence of the leiomyosarcoma.

proteins. The final diagnosis was of a well-differentiated grade I LMS. ${ }^{6}$

As a result of this diagnosis, further surgery was deemed necessary. Preoperatively, a contrast computed tomography (CT) scan showed thickening of the soft tissue adjacent to the inferior right hemimandibular surface, without bone or neck lymph node involvement. A metastatic work-up was negative, including $\mathrm{CT}$ imaging of the chest, abdomen and pelvis and a bone scan. A gynaecological examination and transvaginal ultrasound was also normal. However, an magnetic resonance imaging (MRI) scan showed increased mucosal impregnation near teeth number 46 and 47. Subsequently, under general anaesthesia an excision of the perilesional mucosa, a partial bone resection sparing the lingual and mandibular nerves and the extraction of teeth number 45-48 was performed [Figure 4A]. Postoperatively, the patient was prescribed antibiotics ( $1 \mathrm{~g}$ of ceftriaxone per day) along with an anti-discolouration mouthwash containing $0.2 \%$ chlorhexidine and hyaluronic acid.

The patient was discharged two days later with no complications. Every three months, she attended follow-up appointments wherein MRI and chest and abdominal ultrasounds were performed. A wholebody CT scan was also undertaken six months after the surgery, with positron-emission tomography/CT performed at 12 months. At the time of writing, 20 months after the radical surgery, there were no signs of local recurrence or metastasis and the patient appeared healthy [Figure 4B].

\section{Discussion}

Smooth muscle tumours rarely develop in the head and neck region; however, if present, they occur mainly in the walls of blood vessels, the erector pili musculature of the skin, the circumvallate papillae of the tongue and in the myoepithelial cells of the salivary glands. ${ }^{\text {? }}$ Soft tissue LMS can be divided into retroperitoneal/ intra-abdominal, cutaneous/subcutaneous and vascular subgroups, with distinct clinical and biological differences despite their similar histology. ${ }^{8}$ The most common intraoral site for LMS appears to be the tongue, usually as a result of metastasis from a primary tumour in the uterus, gastrointestinal tract or retroperitoneum. ${ }^{7,9}$ Oral LMS may also involve the jaw bones, cheek, gingiva, floor of the mouth, mandible, soft or hard palate and lips. These tumours present with a wide range of clinical features, including painless or painful smooth rubbery firm masses with or without ulceration, tooth mobility, epistaxis, nasal obstruction, otalgia and a variety of other symptoms depending on the site of the lesion. ${ }^{2-5,8,10}$

Clinically, oral LMS is often confused with other benign and malignant lesions. With regards to the current patient, the clinical and macroscopic features of the case ostensibly mimicked a benign lesion. This was further compounded by the young age of the patient and the well-circumscribed growth of the swelling. Among benign tumours, the most problematic entity to exclude during the differential diagnosis is a leiomyoma, as well-differentiated LMS may show similar microscopic features, including a 'pushing' growth pattern; as a result, the absence of mitoses is the major differentiating factor. ${ }^{10}$ In the present case, mitoses were clearly observed, along with other features of malignancy including nuclear atypia and necrosis. Due to the insidious clinical presentation of LMS, histopathological analysis is critical to exclude other benign lesions such as fibromas, haemangiomas, neurofibromas, schwannomas and peripheral giant cell granulomas. The rapid growth of a lesion in a young patient and certain histological features may also suggest nodular fasciitis, although this is rare in the orofacial area and is usually characterised by selflimiting growth, mitotic activity and focal infiltration. ${ }^{11}$

Microscopically, a solitary fibrous tumour was also excluded in the current case as this entity is rarely reported in the oral cavity. ${ }^{10}$ Other malignancies with spindle cell morphology include squamous cell carcinomas, gastrointestinal stromal tumours, fibrosarcomas, myofibroblastic sarcomas, melanomas, rhabdomyosarcomas and spindle cell myoepithelial carcinomas. ${ }^{11-17}$ In particular, myofibroblastic sarcomas and rhabdomyosarcomas also affect younger individuals, 
Table 1: Differential histopathological diagnoses of leiomyosarcoma ${ }^{1-17}$

\begin{tabular}{|c|c|}
\hline $\begin{array}{l}\text { Differential } \\
\text { diagnosis }\end{array}$ & Histopathological features \\
\hline Fibroma & $\begin{array}{l}\text { - Usually abundant fibrous stroma } \\
\text { - Immunonegative for h-caldesmon }\end{array}$ \\
\hline $\begin{array}{l}\text { Head and neck } \\
\text { leiomyoma }\end{array}$ & - No mitoses \\
\hline $\begin{array}{l}\text { Lobular capillary } \\
\text { haemangioma/ } \\
\text { pyogenic granuloma }\end{array}$ & - Proliferation of capillary vessels \\
\hline $\begin{array}{l}\text { Neurofibroma/ } \\
\text { schwannoma }\end{array}$ & $\begin{array}{c}\text { - Absence of perpendicularly } \\
\text { oriented fascicles of spindle cells } \\
\text { - Pointed rather than blunt-ended } \\
\text { nuclei } \\
\text { - Immunopositive for S100 proteins } \\
\text { and other neural markers } \\
\text { - Immunonegative for muscle } \\
\text { markers }\end{array}$ \\
\hline Nodular fasciitis & $\begin{array}{l}\text { - Absence of perpendicularly } \\
\text { oriented fascicles of spindle cells } \\
\text { - Blunt-ended hyperchromatic } \\
\text { nuclei and paranuclear vacuoles }\end{array}$ \\
\hline $\begin{array}{l}\text { Peripheral giant cell } \\
\text { granuloma }\end{array}$ & $\begin{array}{c}\text { - Patternless proliferation } \\
\text { of mononuclear cells with } \\
\text { multinucleated giant cells } \\
\text { - Immunopositive for macrophage } \\
\text { and osteoclast markers } \\
\text { - A vascular background with } \\
\text { haemorrhagic material }\end{array}$ \\
\hline $\begin{array}{l}\text { Solitary fibrous } \\
\text { tumour }\end{array}$ & $\begin{array}{c}\text { • Storiform pattern } \\
\text { - Ovoid to spindle CD34-positive } \\
\text { fibroblasts } \\
\text { - In a collagenous stroma, with } \\
\text { stellate to 'stag-horn'-shaped } \\
\text { vessels }\end{array}$ \\
\hline $\begin{array}{l}\text { Gastrointestinal } \\
\text { stromal tumour }\end{array}$ & $\begin{array}{l}\text { - Immunopositive for c-Kit, CD34 } \\
\text { and DOG1 }\end{array}$ \\
\hline Fibrosarcoma & $\begin{array}{l}\text { - Fascicles of uniform spindle cells } \\
\text { - Tapered nuclei intersecting in a } \\
\text { 'herringbone'-like pattern }\end{array}$ \\
\hline Melanoma & $\begin{array}{l}\text { • Variably pigmented and } \\
\text { haphazardly arranged cells, either } \\
\text { epithelioid or spindle-shaped } \\
\text { - Immunopositive for S100 proteins } \\
\text { and other melanocytic markers } \\
\text { - Immunonegative for smooth } \\
\text { muscle markers }\end{array}$ \\
\hline $\begin{array}{l}\text { Myofibroblastic } \\
\text { sarcoma }\end{array}$ & $\begin{array}{c}\text { - Fibromatosis-like features } \\
\text { - Negative for SMM and } \\
\text { h-caldesmon }\end{array}$ \\
\hline Rhabdomyosarcoma & $\begin{array}{l}\text { - Immunopositive for skeletal } \\
\text { muscle markers } \\
\text { - Immunonegative for smooth } \\
\text { muscle markers }\end{array}$ \\
\hline $\begin{array}{l}\text { Spindle cell/ } \\
\text { sarcomatoid } \\
\text { carcinoma }\end{array}$ & $\begin{array}{l}\text { - Organised fascicular pattern } \\
\text { - Usually immunopositive for } \\
\text { cytokeratins } \\
\text { - Immunonegative for smooth } \\
\text { muscle markers }\end{array}$ \\
\hline
\end{tabular}

$C D=$ cluster of differentiation; $S M M=$ smooth muscle myosin . with the former showing local destructive growth. ${ }^{13,16}$ Squamous cell carcinomas and their rarer spindle cell variants, sarcomatoid carcinomas, are the most frequent overall and spindle cell malignancies in the oral cavity, respectively. ${ }^{10,11,17}$ As such, all other malignant lesions with a spindle cell morphology were excluded in the present case due to their rare occurrence at this site. Moreover, the morphological features of the lesion-including the fascicles of spindle-shaped cells with abundant eosinophilic cytoplasm, bluntended cigar-shaped nuclei, high mitotic rate and pleomorphism-were consistent with a diagnosis of LMS; this was also supported by the immunohistochemical results of an extensive panel of antibodies. ${ }^{8,18}$ While metastasis from primary LMS arising in another site could not be excluded histologically, a high percentage of uterine LMS express oestrogen and/or progesterone receptors, which were negative in this case. ${ }^{19}$ Table 1 summarises the main differential diagnoses of LMS and their various histopathological features. ${ }^{1-17}$

Besides early diagnosis, the prognosis of oral LMS patients depends on the tumour grade, size, site and treatment. ${ }^{20-22}$ Currently, there are no standard criteria for therapy, although the complete excision of the tumour with wide surgical margins is recommended. ${ }^{7,23,24}$ The five-year survival rate among patients with primary oral LMS is $55 \%$, with bone involvement and metastasis significantly associated with poorer prognosis. ${ }^{24}$ Lung and cervical lymph node metastases frequently occur, with the regional lymph nodes affected in $>15 \%$ of oral LMS cases. ${ }^{4}$ Distant metastases, mostly in the lungs, occur in approximately $39 \%$ of patients with oral LMS; in addition, LMS lesions arising in the uterus, gastrointestinal tract and retroperitoneum sometimes metastasise to the lungs, brain, bone and oral cavity.,25 As such, preoperative staging of the whole body is mandatory. In the present case, the regional lymph nodes were free and systemic tests did not reveal any metastasis; hence, no adjuvant therapy was given. However, regular follow-up is essential to rapidly detect recurrence.

\section{Conclusion}

Smooth muscle tumours of the oral cavity are exceedingly rare. A diagnosis of oral LMS should be established histologically and supported by immunohistochemical analysis using specific markers. In certain cases, such as the one presented here, early 
radical excision constitutes the treatment of choice. Critically, LMS should be considered in the differential diagnosis of oral masses as early diagnosis and aggressive treatment are essential to ensure a good prognosis and patient survival. Lifelong periodical follow-up is also recommended.

\section{References}

1. Zanakis SN, Lyris V, Kyriakou S, Agrogiannis G, Korkolopoulou P. Primary leiomyosarcoma of the mandibular gingiva. Glob J Cancer Ther 2016; 2:1-4.

2. Al-Bayaty H, Balkaran RL. Spindle cell carcinoma of the mandible: Clinicopathological and immunohistochemical characteristics. J Oral Biol Craniofac Res 2016; 6:160-3. doi: 10.1016/j.jobcr.2015.08.009.

3. Vilos GA, Rapidis AD, Lagogiannis GD, Apostolidis C. Leiomyosarcomas of the oral tissues: Clinicopathologic analysis of 50 cases. J Oral Maxillofac Surg 2005; 63:1461-77. doi: 10.1016/j.joms.2005.06.018.

4. Schenberg ME, Slootweg PJ, Koole R. Leiomyosarcomas of the oral cavity: Report of four cases and review of the literature. J Craniomaxillofac Surg 1993; 21:342-7. doi: 10.1016/s10105182(05)80495-0.

5. Yan B, Li Y, Pan J, Xia H, Li LJ. Primary oral leiomyosarcoma: A retrospective clinical analysis of 20 cases. Oral Dis 2010; 16:198-203. doi: 10.1111/j.1601-0825.2009.01635.x.

6. Neuville A, Chibon F, Coindre JM. Grading of soft tissue sarcomas: From histological to molecular assessment. Pathology 2014; 46:113-20. doi: 10.1097/PAT.0000000000000048.

7. Amarapala H, Tilakaratne WM. Leiomyosarcoma of the oral cavity: Report of seven cases and review of literature. Oral Oncol Extra 2006; 42:14-17. doi: 10.1016/j.ooe.2005.08.001

8. Weiss SW, Goldblum JR. Enzinger and Weiss's Soft Tissue Tumors, 5th ed. Missouri, USA: Mosby, 2008. Pp. 545-64.

9. Xiao W, Mohseny AB, Hogendoorn PC, Cleton-Jansen AM. Mesenchymal stem cell transformation and sarcoma genesis. Clin Sarcoma Res 2013; 3:10. doi: 10.1186/2045-3329-3-10.

10. International Agency for Research on Cancer. WHO Classification of Head and Neck Tumours, 4th ed. Geneva, Switzerland: WHO, 2017. Pp. 35-47.

11. Regezi JA, Sciubba JJ, Jordan RC. Oral Pathology: Clinical pathologic correlations, 7th ed. Philadelphia, Pennsylvania, USA: Saunders, 2016. Pp. 161-71.

12. Friedrich RE, Zustin J. Late metastasis of gastrointestinal stromal tumour to the oral cavity. Anticancer Res 2010; 30:4283-8.
13. Demarosi F, Bay A, Moneghini L, Carrassi A. Low-grade myofibroblastic sarcoma of the oral cavity. Oral Surg Oral Med Oral Pathol Oral Radiol Endod 2009; 108:248-54. doi: 10.1016/j.tripleo.2009.03.031.

14. Perez-Montiel MD, Plaza JA, Dominguez-Malagon H, Suster S. Differential expression of smooth muscle myosin, smooth muscle actin, h-caldesmon, and calponin in the diagnosis of myofibroblastic and smooth muscle lesions of skin and soft tissue. Am J Dermatopathol 2006; 28:105-11. doi: 10.1097/01. dad.0000200009.02939.cc.

15. Warszawik-Hendzel O, Słowińska M, Olszewska M, Rudnicka L. Melanoma of the oral cavity: Pathogenesis, dermoscopy, clinical features, staging and management. J Dermatol Case Rep 2014; 8:60-6. doi: 10.3315/jdcr.2014.1175.

16. Tandon A, Sethi K, Pratap SA. Oral rhabdomyosarcoma: A review. J Clin Exp Dent 2012; 4:e302-8. doi: 10.4317/jced.50926.

17. Kane SV, Bagwan IN, Shet T, Bavi P, D'Cruz A. Spindle cell myoepithelial carcinoma of the oral cavity: A report of two cases. Oral Oncol Extra 2006; 42:66-9. doi: 10.1016/j. ooe.2005.09.002

18. Rodini CO, Pontes FS, Pontes HA, Santos PS, Magalhães MG, Pinto DS Jr. Oral leiomyosarcomas: Report of two cases with immunohistochemical profile. Oral Surg Oral Med Oral Pathol Oral Radiol Endod 2007; 104:e50-5. doi: 10.1016/j. tripleo.2007.05.005.

19. Hensley ML, Barrette BA, Baumann K, Gaffney D, Hamilton AL, Kim JW, et al. Gynecologic Cancer InterGroup (GCIG) consensus review: Uterine and ovarian leiomyosarcomas. Int J Gynecol Cancer 2014; 24:S61-6. doi: 10.1097/IGC.000000000 0000261 .

20. Suárez-Alén F, Otero-Rey E, Peñamaría-Mallón M, GarcíaGarcía A, Blanco-Carrión A. Oral leiomyosarcoma: The importance of early diagnosis. Gerodontology 2015; 32:314-17. doi: 10.1111 /ger.12126.

21. de Bree R, van der Waal I, de Bree E, Leemans CR. Management of adult soft tissue sarcomas of the head and neck. Oral Oncol 2010; 46:786-90. doi: 10.1016/j.oraloncology.2010.09.001.

22. Gupta R, Astekar M, Dandriyal R, Manjunath BS. Leiomyosarcoma of maxilla: A case report with review of literature. J Exp Ther Oncol 2015; 11:147-53.

23. Akcam T, Oysul K, Birkent H, Gerek M, Yetiser S. Leiomyosarcoma of the head and neck: Report of two cases and review of the literature. Auris Nasus Larynx 2005; 32:209-12. doi: 10.1016/j.anl.2005.01.012.

24. Ethunandan M, Stokes C, Higgins B, Spedding A, Way C, Brennan P. Primary oral leiomyosarcoma: A clinico-pathologic study and analysis of prognostic factors. Int J Oral Maxillofac Surg 2007; 36:409-16. doi: 10.1016/j.ijom.2006.12.015.

25. Kaziro GS. Metastatic uterine leiomyosarcoma to the tongue: Report of case. J Oral Surg 1981; 39:128-9. 